\title{
Aggregated Molecular Fluorophores in the Ammonothermal Synthesis of Carbon Dots
}

\author{
Claas J. Reckmeier, ${ }^{\dagger}$ Julian Schneider, ${ }^{\dagger}$ Yuan Xiong, ${ }^{\dagger}$ Jonas Häusler, ${ }^{\dagger}$ Peter Kasák, ${ }^{\S}$ \\ Wolfgang Schnick, ${ }^{\ddagger}$ and Andrey L. Rogach ${ }^{\dagger *}$ \\ †Department of Materials Science and Engineering \& Center for Functional Photonics (CFP), City University of Hong Kong, \\ 83 Tat Chee Avenue, Kowloon, Hong Kong S.A.R. \\ ${ }^{\ddagger}$ Department of Chemistry, Ludwig-Maximilians-Universität München, Butenandtstr. 5-13 (D), 81377 Munich, Germany \\ ${ }^{\S}$ Center for Advanced Materials, Qatar University, PO Box 2713, Doha, Qatar \\ *Corresponding author. Email: andrey.rogach@ @ityu.edu.hk
}

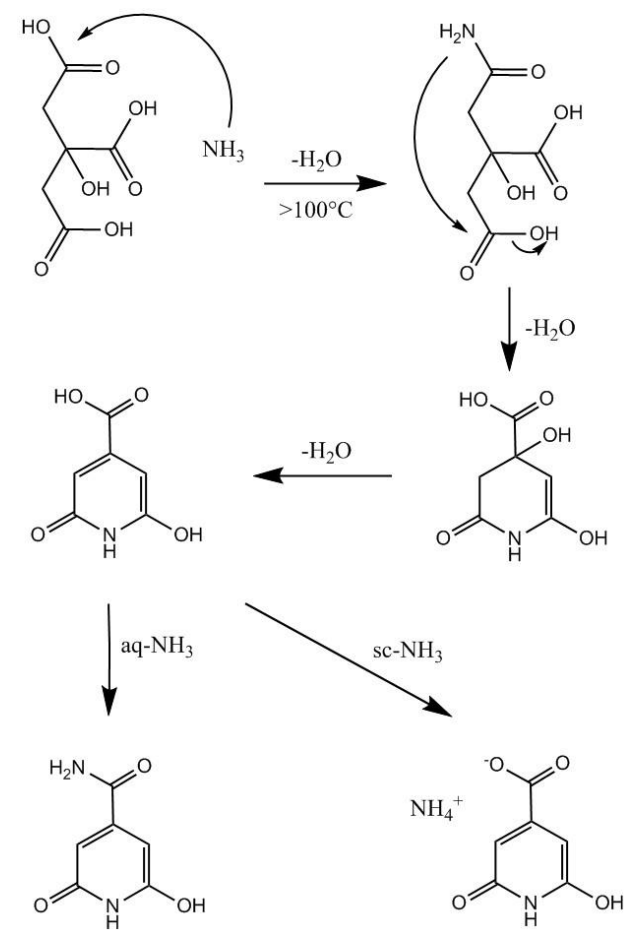

Figure S1: Intramolecular condensation and cyclization of an amide derivative of citric acid, as initially described by Behrmann and Hofmann and Sell and Easterfield. ${ }^{1-3}$ The reactions in our case (according to our XPS and FTIR studies) predominantly yield the amide derivative of citrazinic acid in the hydrothermal reaction $\left(\right.$ aq- $\left.\mathrm{NH}_{3}\right)$, and the ammonium salt of citrazinic acid and its aggregates in the ammonothermal reaction $\left(\mathrm{sc}-\mathrm{NH}_{3}\right)$. 


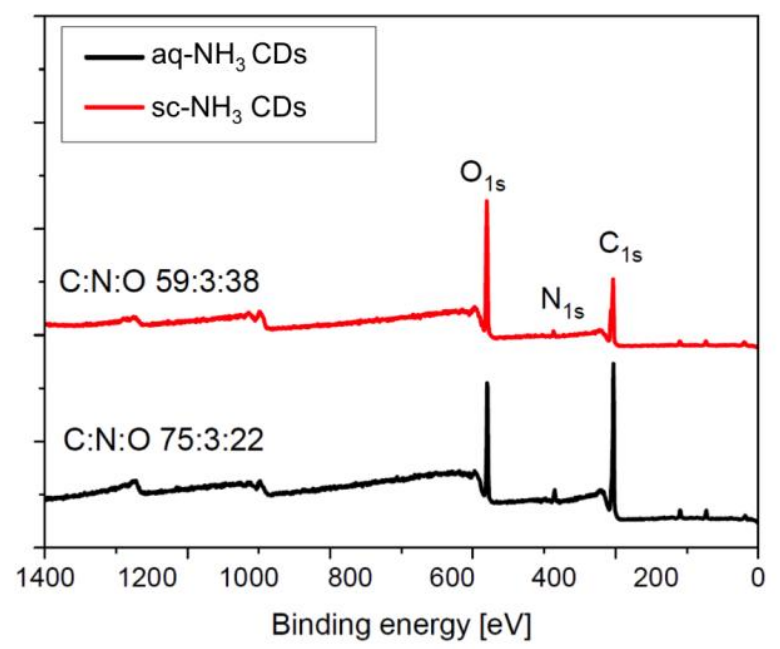

Figure S2: Full XPS spectra of aq- $\mathrm{NH}_{3}$ and sc- $\mathrm{NH}_{3}$ CDs.
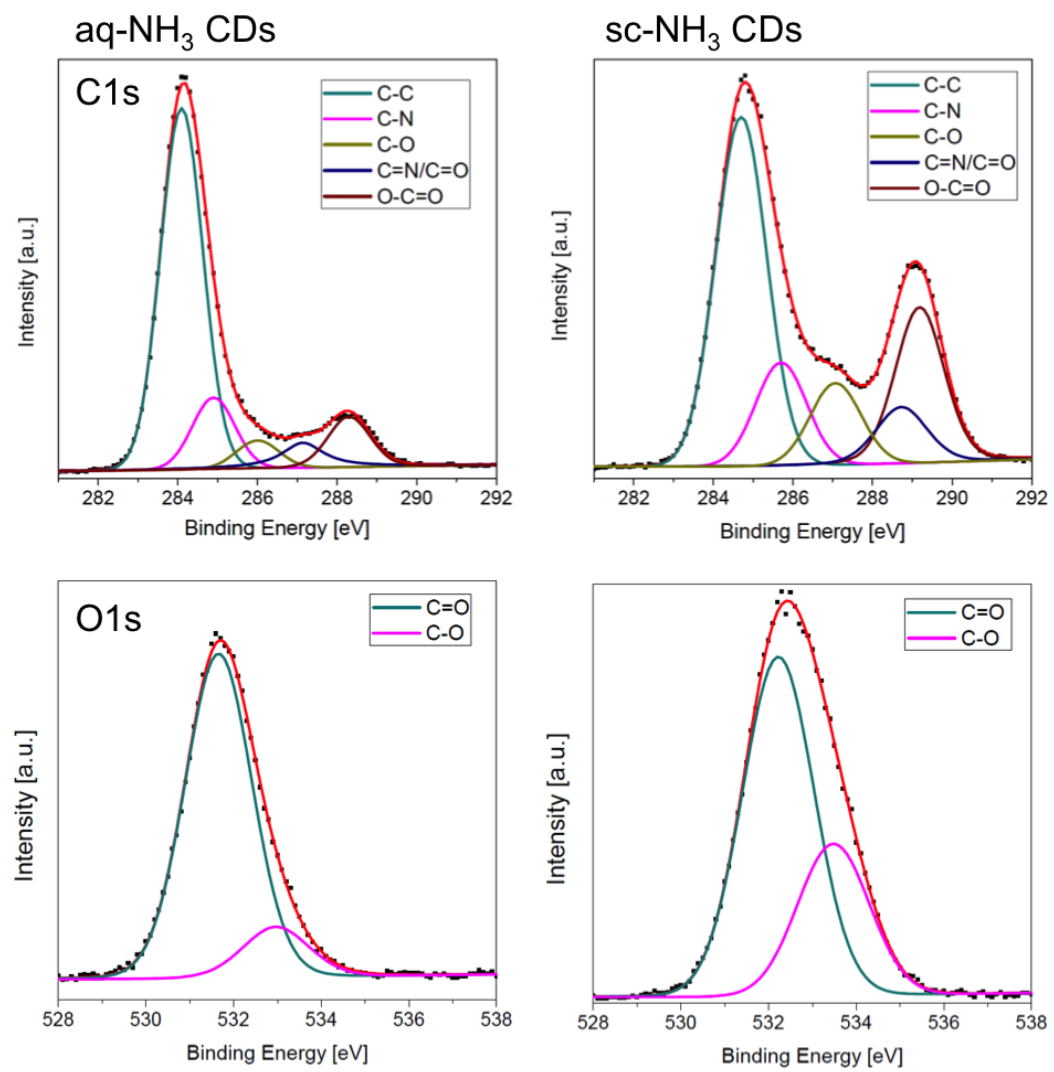

Figure S3: XPS C $1 \mathrm{~S}$ and O $1 \mathrm{~S}$ spectra of aq- $\mathrm{NH}_{3}$ and sc- $\mathrm{NH}_{3} \mathrm{CDs}$. In aq- $\mathrm{NH}_{3} \mathrm{CDs}$, the high concentration of the amide instead of the carboxylic acid is visible by the stronger contribution from $\mathrm{C}-\mathrm{N}$ and the reduced signal strength of the $\mathrm{C}-\mathrm{O}$ band in the $\mathrm{C} 1 \mathrm{~s}$. Furthermore, the weak $\mathrm{C}-\mathrm{O}$ band in the $\mathrm{O} 1 \mathrm{~S}$ supports these results. On the other hand, the strong carboxylic functionality in $\mathrm{sc}-\mathrm{NH}_{3} \mathrm{CDs}$ can be observed by the increased $\mathrm{C}-\mathrm{O}$ band in both the $\mathrm{C} 1 \mathrm{~S}$ and $\mathrm{O} 1 \mathrm{~S}$ spectra. Higher contribution from $\mathrm{C}=\mathrm{O}$ in both cases can be related to the presence of additional carbonyl groups in citrazinic acid. Note the general shift of around $1 \mathrm{eV}$ to higher binding energies for sc- $\mathrm{NH}_{3} \mathrm{CDs}$. 


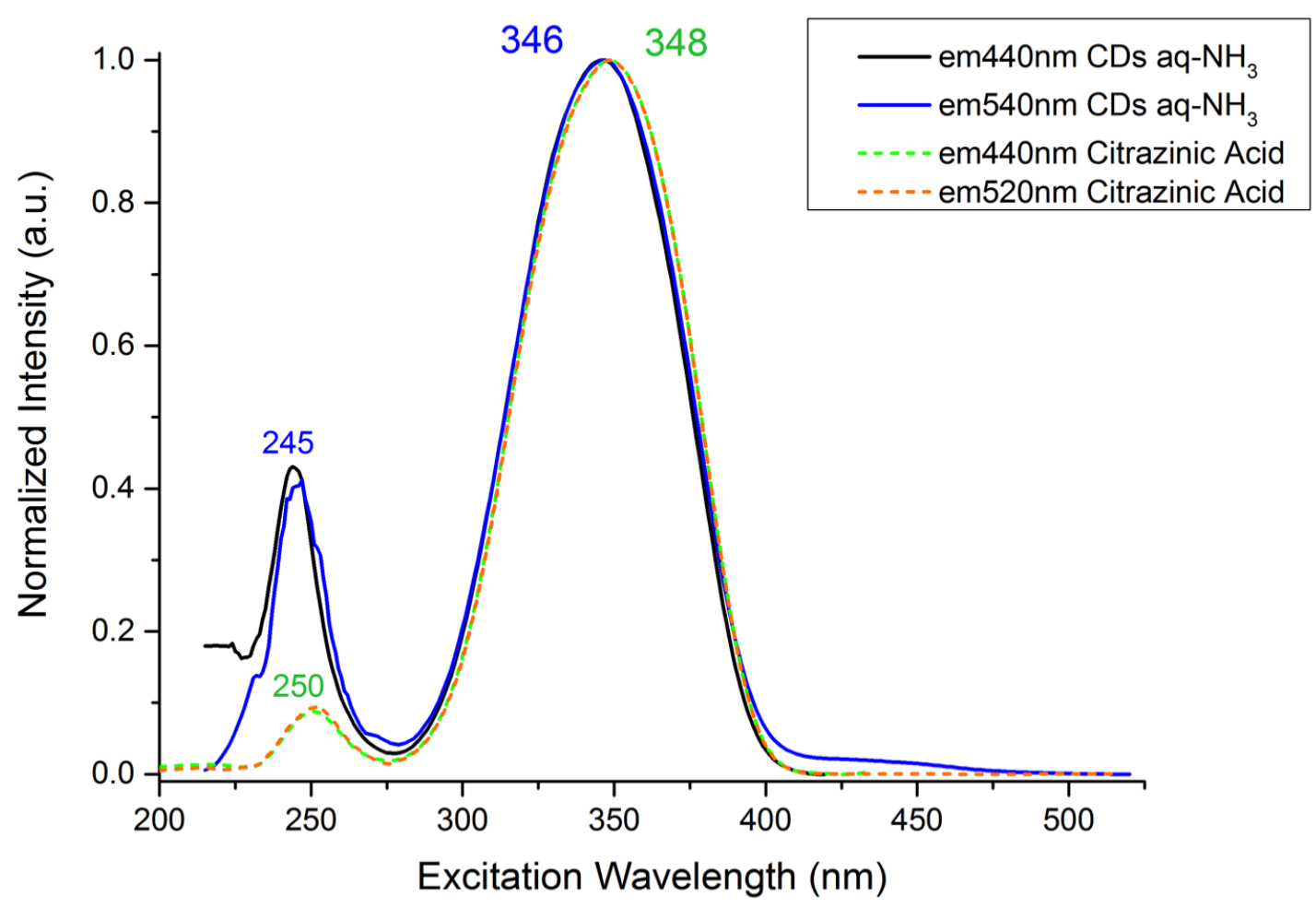

Figure S4: PLE spectra of aq- $\mathrm{NH}_{3}$ CDs (solid line) and citrazinic acid (dashed line) at different detection wavelengths characterizing the existing emission centers.
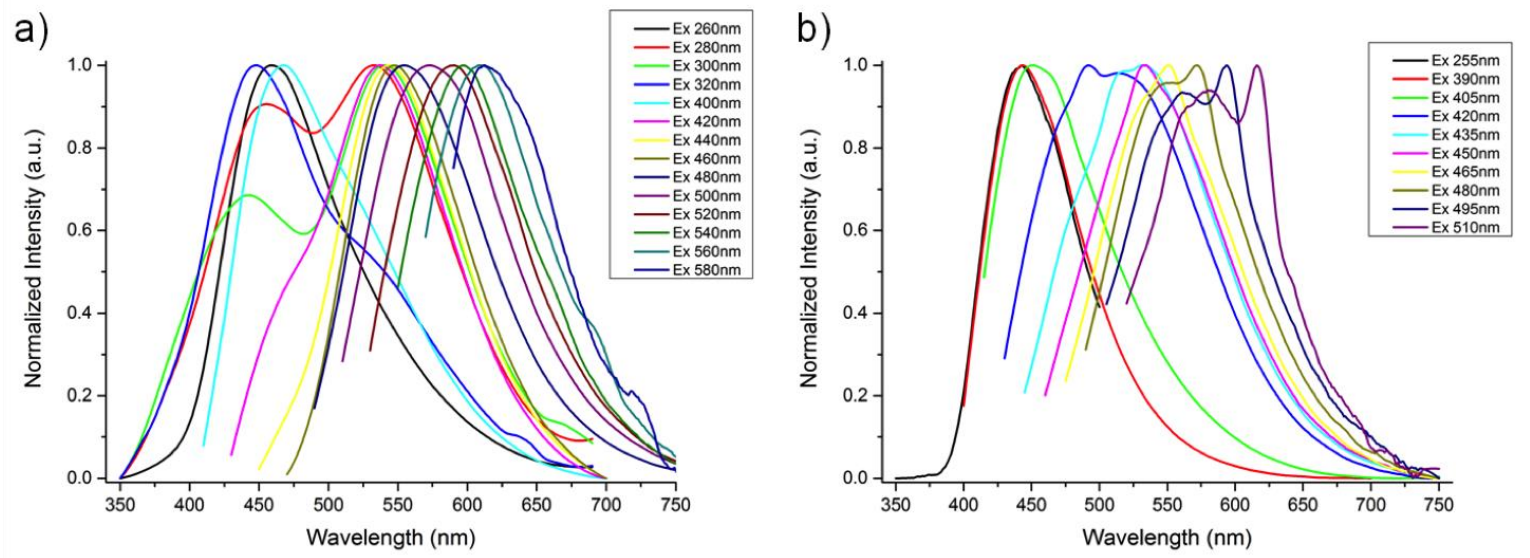

Figure S5: Normalized PL spectra of (a) sc- $\mathrm{NH}_{3} \mathrm{CDs}$ and (b) aq- $\mathrm{NH}_{3}$ CDs highlighting the long wavelength excitation and emission while showing only short wavelength excitations of interest. Both CD samples show an excitation dependent emission, but aq- $\mathrm{NH}_{3} \mathrm{CDs}$ (b) have significantly weaker long wavelength emission. The additional peaks seen in (b) are due to Raman scattering (visible because of the low emission intensity). 
Figure S5 shows excitation dependent PL spectra of the two CD samples with a focus on the long wavelength emission and the double peaks. Figure S5a demonstrates that the red component of the double peak is the red-shifted peak with the highest (peak) emission energy. The emission intensity of the red-shifted peaks of aq- $\mathrm{NH}_{3} \mathrm{CDs}$ in Figure $\mathrm{S} 5 \mathrm{~b}$ is very weak. A sufficient signal could only be detected up to an excitation of $510 \mathrm{~nm}$. Raman scattering of water is visible in all red-shifted peaks, demonstrating the overall low emission intensity (Figure $\mathrm{S} 5 \mathrm{~b}$ ). However, the fact that aq- $\mathrm{NH}_{3} \mathrm{CDs}$ possess an excitation dependent emission shows that they do not only consist of fluorophores such as citrazinic acid but have a small amount of low energy emitting states. These could either be surface states of the $\mathrm{sp}^{2} / \mathrm{sp}^{3} \mathrm{CDs}$, or low energy states of fluorophore dimers or trimers.

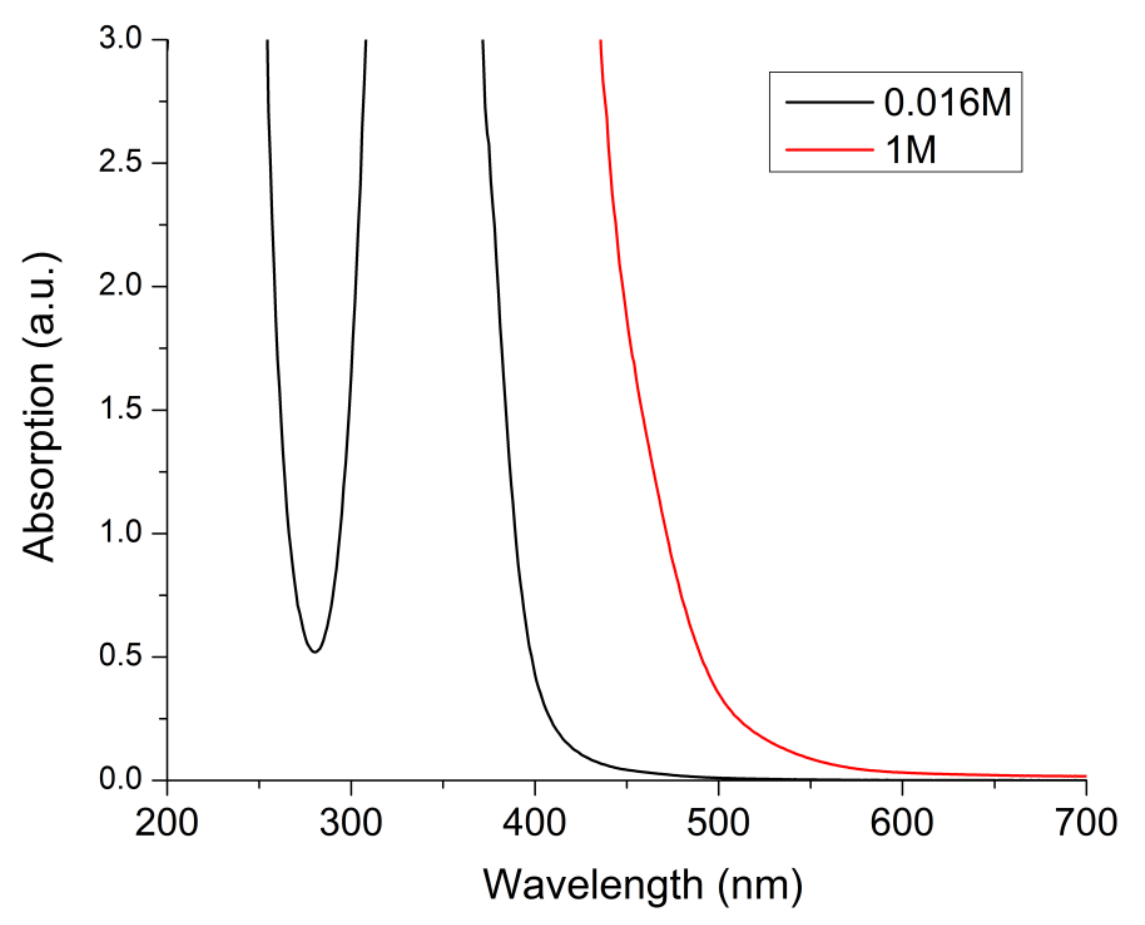

Figure S6: Absorption spectra of highly concentrated citrazinic acid solutions, showing no additional features in the long wavelength absorption. Due to the high concentration, the peak can't be resolved and naturally extends into the longer wavelength region. However, this shift is in stark contrast to the effects of aggregation, which creates additional states at long wavelengths, even at low concentrations, as revealed in Figure 4. 


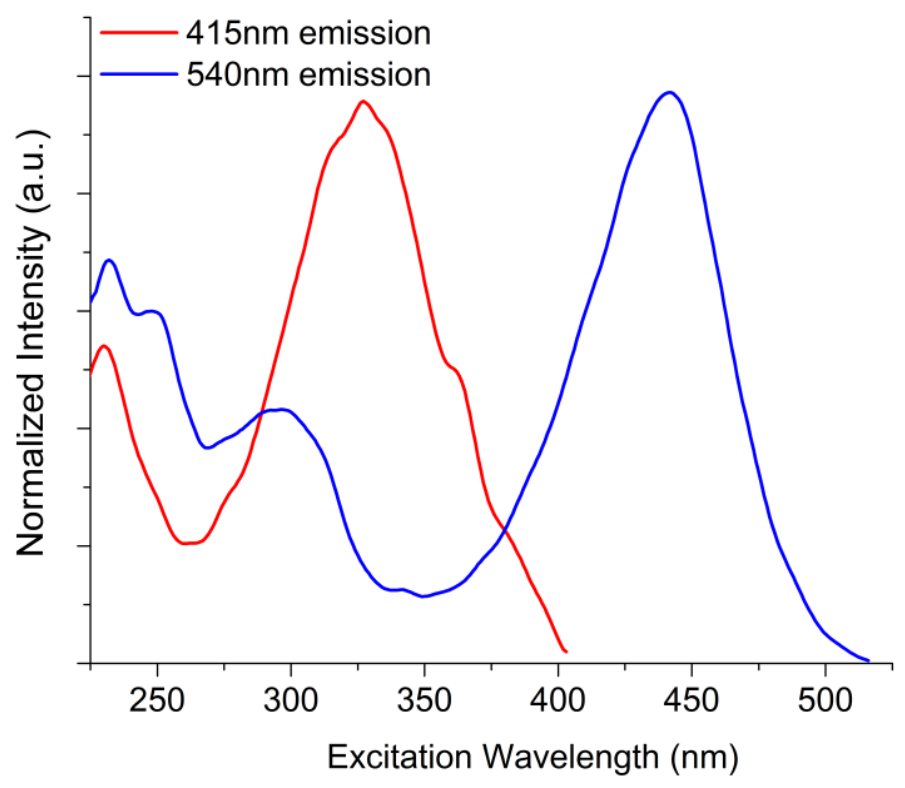

Figure S7: PLE spectra recorded at emission wavelengths of $415 \mathrm{~nm}$ and $540 \mathrm{~nm}$ for the aqueous solution of $200 \mathrm{mM}$ citrazinic acid in $4 \mathrm{wt} \%$ PVP after several months of storage.

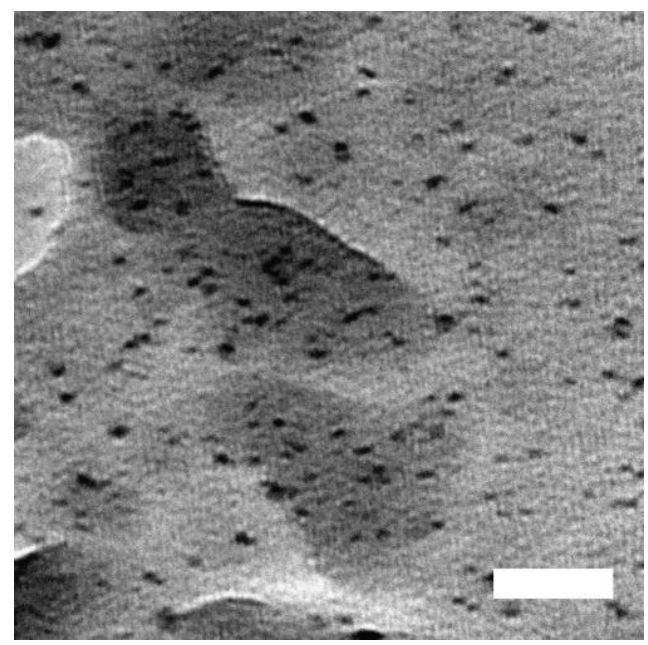

Figure S8: TEM image of the aqueous solution of $200 \mathrm{mM}$ citrazinic acid in $4 \mathrm{wt} \%$ PVP after several months of storage, showing aggregation of the fluorophore into regular particles with a size of $4.5 \pm 1.2 \mathrm{~nm}$. Scale bar of the image is $50 \mathrm{~nm}$. 

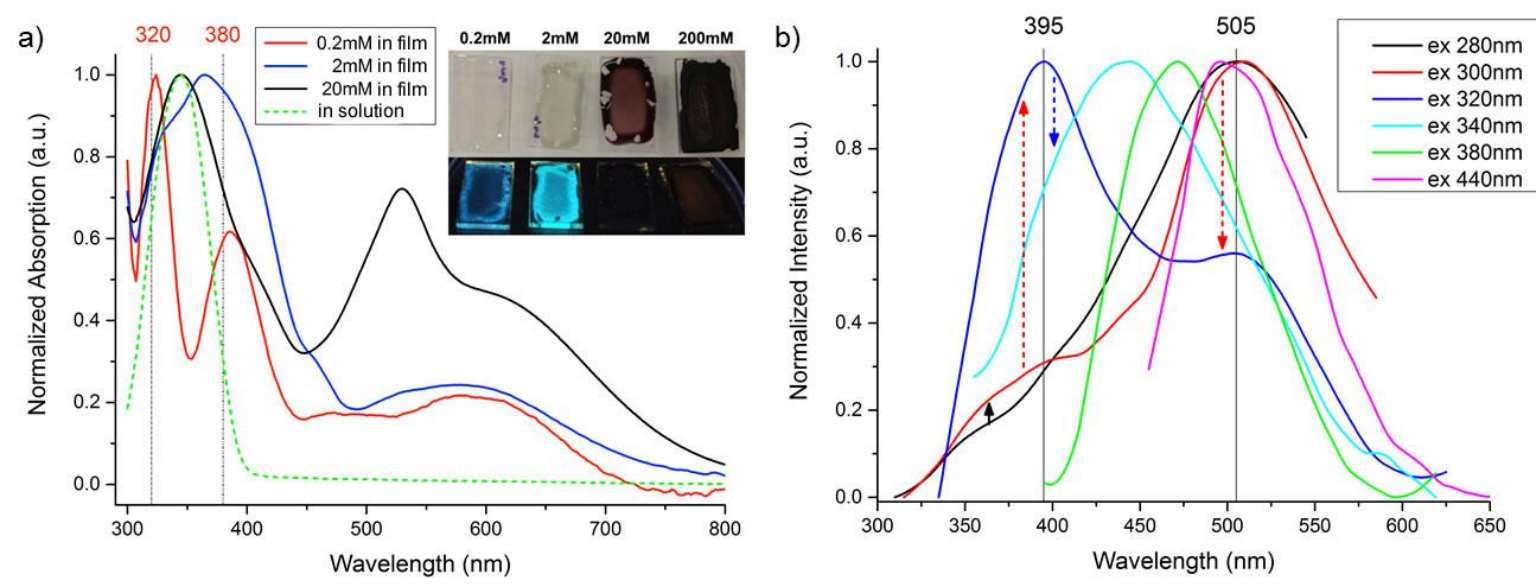

Figure S9: (a) Absorption spectra of PVP films with increasing concentration of citrazinic acid, as indicated. The dashed green line shows the absorption spectrum of citrazinic acid in solution. The film samples show broadened absorption with additional peaks at long wavelengths. However, a detailed analysis of the film absorption is hindered by effects from thin film interference, as exemplified in Figure S10. Inset: Photographs of $\mathrm{PVP} /$ citrazinic acid films taken under ambient light (top) and UV excitation (365 nm, bottom). (b) PL spectra of the $0.2 \mathrm{mM} \mathrm{PVP/citrazinic} \mathrm{acid} \mathrm{film} \mathrm{showcasing} \mathrm{a} \mathrm{double} \mathrm{peak} \mathrm{emission.} \mathrm{High} \mathrm{and} \mathrm{low} \mathrm{energy} \mathrm{excitations}$ $(280-300 \mathrm{~nm}, 449 \mathrm{~nm})$ lead to green emission, while excitation at $320 \mathrm{~nm}$ results in an increased blue emission. Dashed arrows illustrate the respective peak intensity evolution.

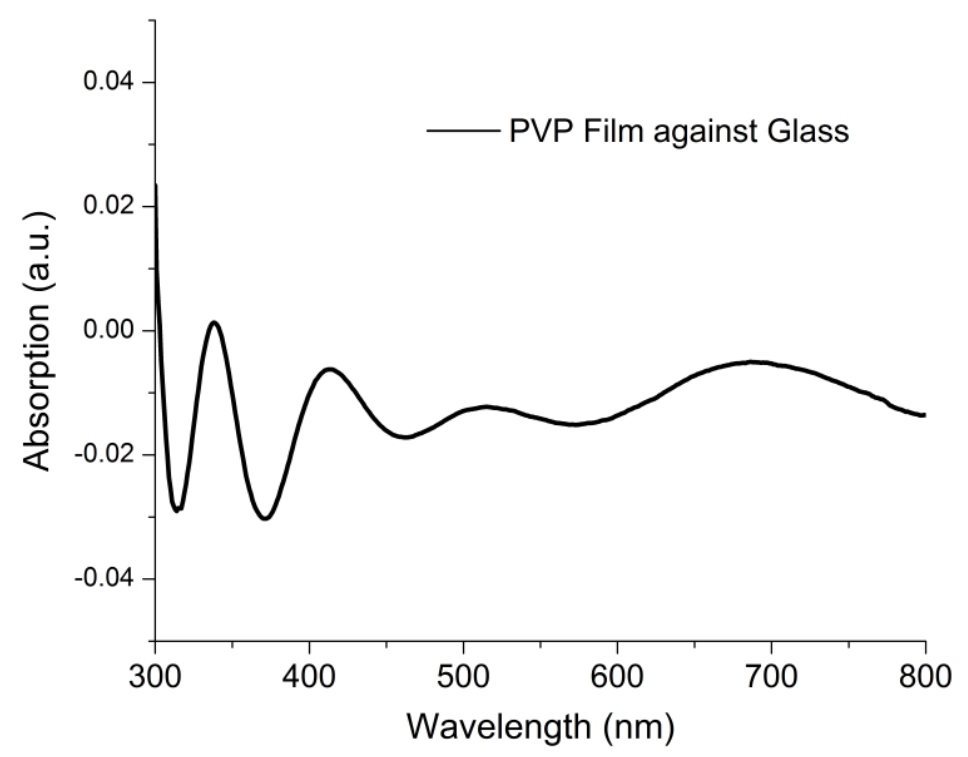

Figure S10: Absorption spectra of a PVP film measured against a glass substrate baseline, indicating the effect of thin film interference. 
a)

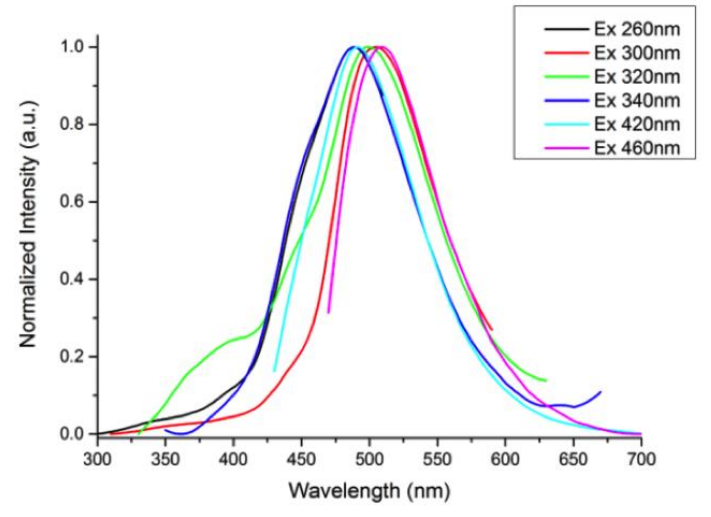

b)

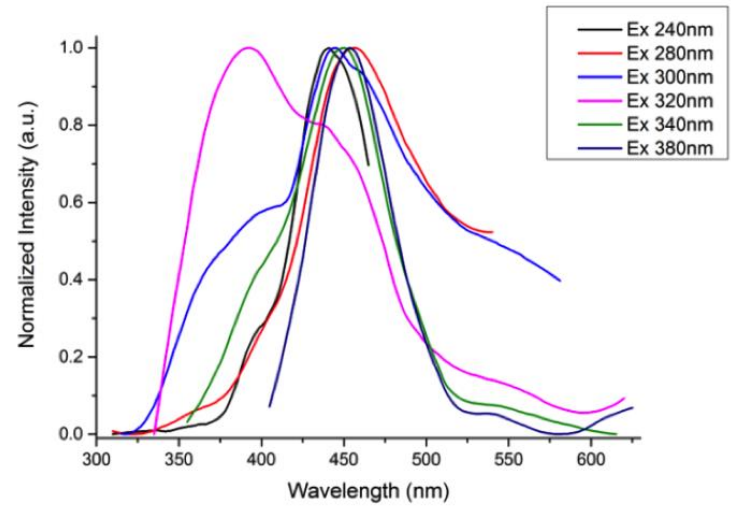

Figure S11: PL of PVP/citrazinic acid films at a) $2 \mathrm{mM}$ and b) $20 \mathrm{mM}$ concentration. Double peak formation is observed.

a)

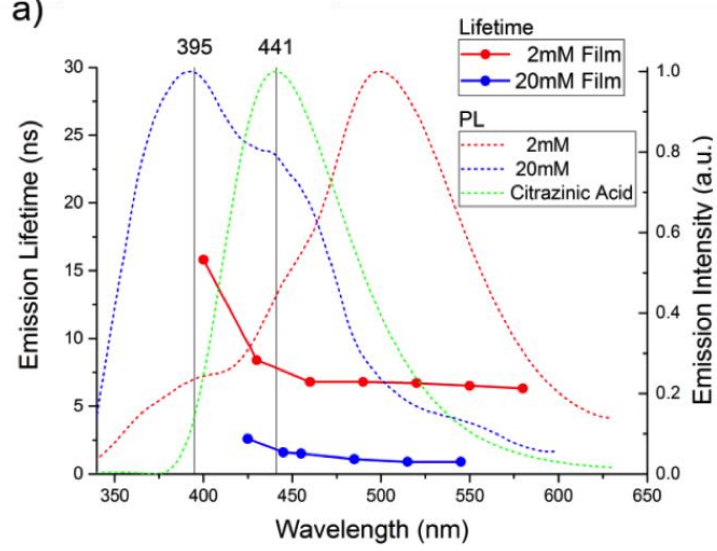

b)

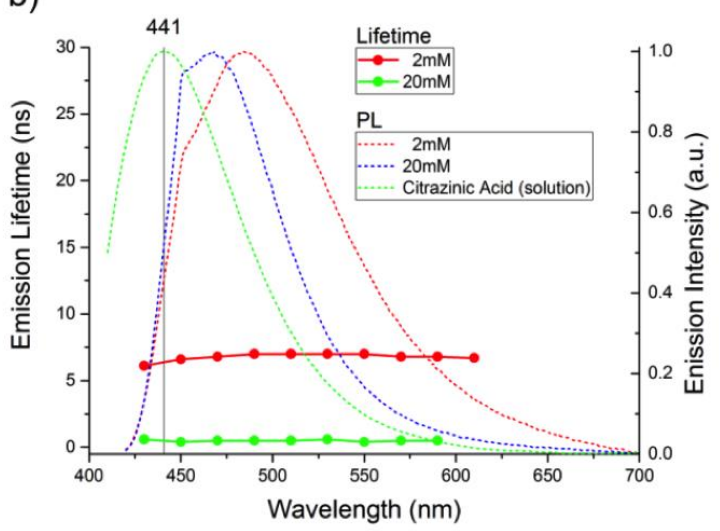

Figure S12: Average PL lifetime over emission wavelengths (solid lines) for PVP/citrazinic acid films of higher concentrations (as indicated on the frames) at (a) $320 \mathrm{~nm}$ excitation and (b) $405 \mathrm{~nm}$ excitation. The dashed lines show representative PL spectra at the respective excitation wavelengths. 


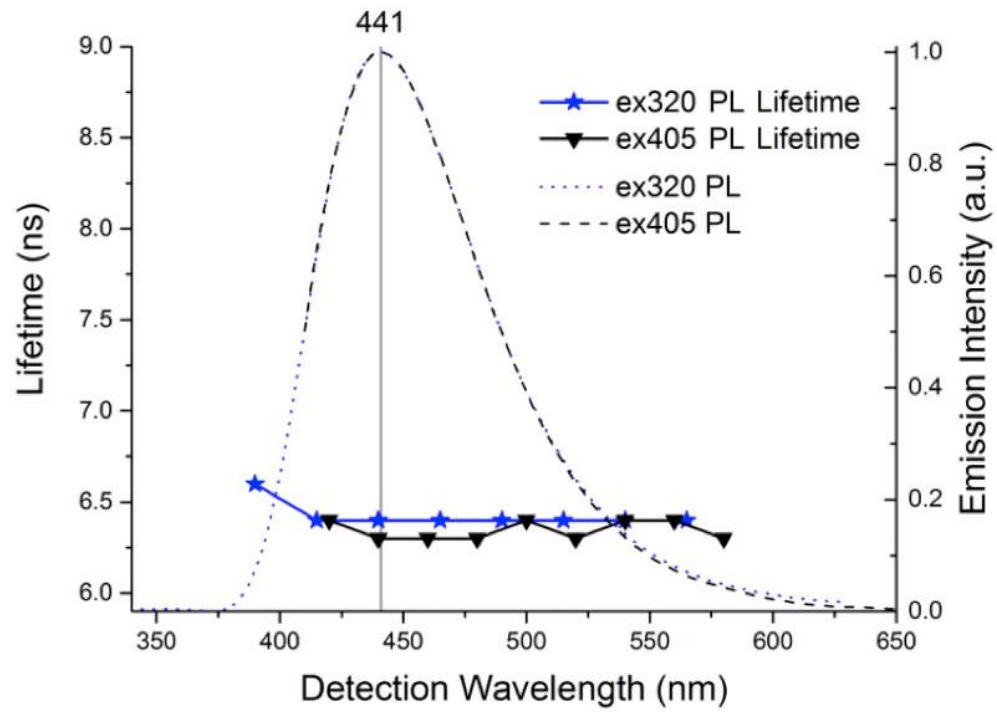

Figure S13: Average emission lifetime of citrazinic acid (CA) fluorophores in solution as a function of the emission/detection wavelength at $320 \mathrm{~nm}$ and $405 \mathrm{~nm}$ excitation. The dashed lines show the corresponding PL spectra at the respective excitation wavelengths. The PL lifetime is almost constant for both excitation wavelengths and for the whole range of detection wavelength, being approximately $6.4 \mathrm{~ns}^{4}$
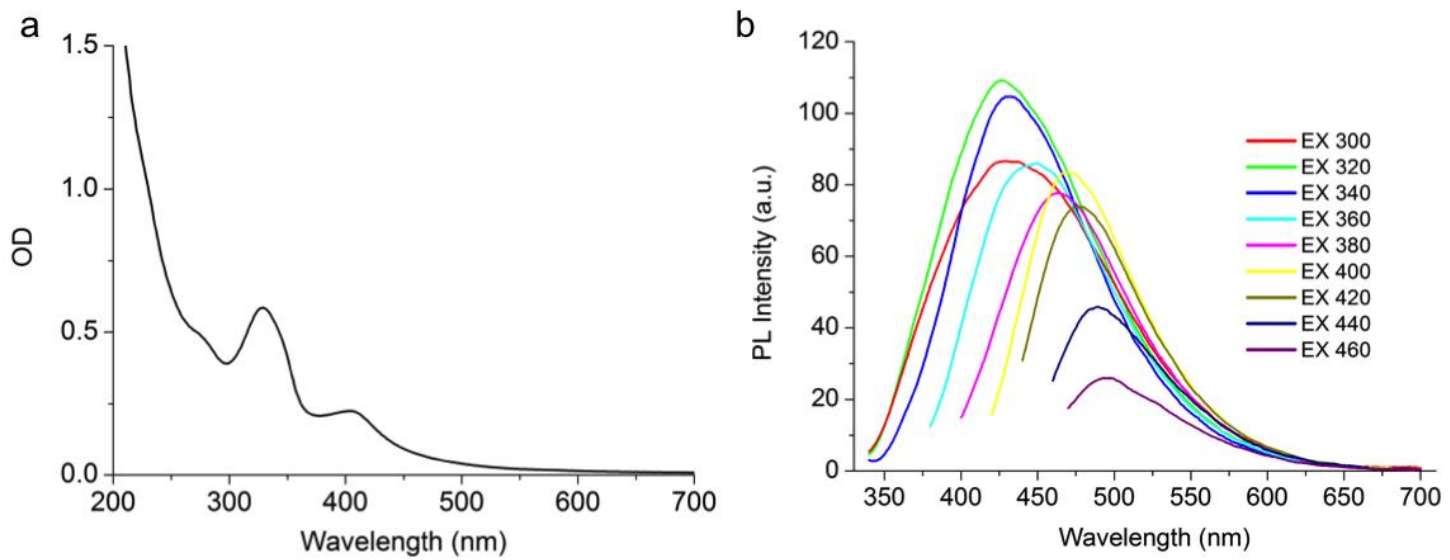

Figure S14: Absorption (a) and excitation dependent PL (b) spectra of citrazinic acid after 5h of hydrothermal treatment at $200{ }^{\circ} \mathrm{C}$. The absorption spectra indicate the formation of states at longer wavelengths, which is further confirmed by the excitation dependent PL. With regard to the overall decrease in PL intensity, such changes can be assigned both to the formation of fluorophore aggregates, as well as carbonized particles, as commonly described in CD related literature. 


\section{References}

(1) Behrmann, A.; Hofmann, A. W., Ueber die Amide der Citronensäure; Umwandlung derselben in Pyridinverbindungen. [About the amides of citric acid; Their transformation into pyridine compounds] Ber. Dtsch. Chem. Ges. 1884, 17, 2681-2699.

(2) Sell, W. J.; Easterfield, T. H., LXXIII.-Studies on citrazinic acid. Part I. J. Chem. Soc., Trans. 1893, 63, 1035-1051.

(3) Easterfield, T. H.; Sell, W. J., V.-Studies on citrazinic acid. Part II. J. Chem. Soc., Trans. 1894, 65, 28-31.

(4) Schneider, J.; Reckmeier, C. J.; Xiong, Y.; von Seckendorff, M.; Susha, A. S.; Kasák, P.; Rogach, A. L., Molecular Fluorescence in Citric Acid-Based Carbon Dots. J. Phys. Chem. C 2017, 121, 2014-2022. 